This is the peer reviewed version of the following article: Yongjiao Yang, Yan Xu \& Mick Wilkinson (2019)

Towards effective mobilization of social participation: from an instrumental approach to a value-oriented approach in China, Policy Studies, which has been published in final form at https://

doi.org/10.1080/01442872.2019.1667966. This article may be used for non-commercial purposes in accordance with Wiley Terms and Conditions for Use of Self-Archived Versions

\title{
Towards Effective Mobilization of Social Participation: From an Instrumental Approach to a Value-oriented Approach in China
}

Authors

1. Yongjiao Yang, $\mathrm{PhD}$ (The first author) is an Associate Professor at the School of Public Affairs, Chongqing University

Address: No.174 Shazhengjie, Shapingba, Chongqing, China, 400044

Phone: +86 18925192901

Email: yangyongjiao11@outlook.com

2. Yan $\mathbf{X u}, \mathrm{PhD}$ (The corresponding author) is an Associate Professor at the School of Sociology and Anthropology, Sun Yat-Sen University

Address: No. 135, Xingang West Road, Haizhu District, Guangzhou, China, 510275

Phone: +86 13066373874

Email: xuyan26@mail.sysu.edu.cn

3. Mick Wilkinson, PhD, is a Lecturer at the School of Education and Social Sciences, University of Hull.

Address: School of Education and Social Sciences, University of Hull, Hull, UK, 
HU6 7RX

Phone: +44 (0) 1482465796

Email: m.d.wilkinson@hull.ac.uk

\section{Acknowledgements}

Funding: This study was funded by The National Social Science Fund of China (NSSFC) (17CSH061).

Conflict of Interest: Dr Yongjiao Yang has received a research grant from The National Social Science Fund of China (NSSFC). The other authors have not received any research grants for this study. The authors declare that they have no conflict of interest. 


\title{
Towards Effective Mobilization of Social Participation: From an Instrumental Approach to a Value-oriented Approach in China
}

\author{
Abstract \\ State mobilization is crucial for promoting social participation in mainland China. Due to its \\ historically weak roots, social participation's limited popularity reflects the failure of China's \\ current instrumental mobilization approach which focuses on risk control, bureaucratism, and \\ implementing top-down directives. As explained in this article, mobilization should be a \\ value-oriented and inclusive process that emphasizes people's happiness rather than achieving \\ bureaucratic goals. This research contributes to the field of study by examining the key \\ elements of value-oriented mobilization based on data from a national, large-scale survey \\ conducted in mainland China. The implications for the development of policy for, and the \\ part nonprofits can play in, social participation mobilization in China are also discussed.
}

\section{Keywords}

Social Participation; Mobilization; Policy Development; Happiness; Migrants 


\section{Introduction}

Social participation (also known as social involvement and social engagement) refers to one’s participation in the collective action of social groups (Prohaska, Anderson and Binstock 2012). Lindström et al. (2002) and Nummela et al. (2008) noted that the term social participation is commonly used to refer to the process of individuals participating in activities initiated and organized by Non-Governmental Organizations (NGOs). In China, social participation normally excludes commercial activities and political engagement, and primarily refers to social interactions such as recreational, fitness, or charitable activities (Hu 2014). A large number of these are organized by NGOs or nonprofit organizations, which are also referred to as social organizations in China.

Social participation is important because it can help increase the quality of individuals' lives (Lee et al. 2007). Social participation theory suggests that involvement in a nonpolitical social organization will mobilize individuals to become politically active, thereby contributing to civil society (Olsen 1972). Other studies have examined the nature of social participation among adolescents and young adults, concluding that it was a significant factor for their development and social adjustment (Cicognanin et al. 2008; West 2008). Furthermore, previous studies have noted that social participation is an indicator of successful aging and is related to the subjective well-being of older people (Zhang and Zhang 2015; Baker et al. 2005). 
Social participation in China is not strong and only became an area of study in the late 1990s. Its weak roots in society are easily explained. Prior to Deng Xiaoping's economic reforms, the nation's danwei system, wherein people were connected, and belonged, to their work units, dominated community life (Xie, Lai and Wu 2009); it left little social space for alternative forms of community organization. Before China's socio-economic reforms of the late 1980s, social services for urban residents were provided almost exclusively through their danwei. As the market economy expanded, the government decentralized and became much less able, or willing, to take full responsibility for the social welfare of urban residents. This led to a growing awareness of the importance of generating social participation as a means for people to identify and fulfill their needs (Abatena 1997).

China's central and local governments have made great efforts to mobilize social participation as a means of implementing social programs, even incentivizing nonprofit organizations to facilitate this process (The State Council Information Office 2016). Along with the emergence of a large number of grassroots NGOs (He 2010), China's citizens are increasingly willing to volunteer their time and labor; this was especially evident during the response to the Sichuan earthquake and the Beijing Olympic Games in 2008. Although in recent years the government has strengthened its regulation of nonprofit organizations, with systemic imperatives such as reintroducing the dual administration system, it has not reduced its efforts to use mobilization to encourage social participation that does not lead to political participation.

China's current mobilization approach is best described as instrumental; its main features are risk control, bureaucratism, and top-down directives from the government (Huang and Ji 2016). 
But, the effectiveness of this approach is far from certain. Plummer and Taylor (2004) identified factors that hindered community participation in urban China: party-state dominance, top-down mobilization methods, a cadre evaluation system focused on outputs rather than on impacts, a lack of financial accountability, and sectoral divisions within government. In general, the instrumental mobilization approach to social participation appears to fail to consider participants' well-being and mobilization's impacts on them. A more effective and socially inclusive approach would be to consider how people's happiness can be increased through the process of mobilization and how social participation activities can attract the most people. Inclusivity is important because China's dramatic transformation over the last four decades has generated large-scale population movements ${ }^{1}$. Social participation activities could be improved by attracting internal migrants as they are often a large but disadvantaged group in urban areas.

Although some studies (e.g. Plummer and Taylor 2004) have pointed out the deficiencies of state-initiated mobilizations in China, few have broadened the discussion to consider more effective alternative approaches. Moreover, few studies have used national survey data to reveal the broader patterns and features of social participation in China. This limitation greatly hinders our understanding of the current forms of social participation and of the strengths and weaknesses of the existing approaches to generating engagement through mobilization.

This article examines the patterns of, and the mobilization techniques used to generate, social participation in China. First, the interpretations of social participation are discussed. Then, value-oriented mobilization is introduced and suggested as a more effective approach compared to instrumental mobilization. It is then investigated at the micro- and the 
macro-levels. At the micro-level, value-oriented mobilization's effectiveness regarding promoting happiness, and the measures for evaluating it, are investigated. At the macro-level, mobilization's effects on internal migrants during urbanization are assessed. These two aspects are appraised using data from China Labor-force Dynamics Survey (CLDS) ${ }^{2}$, a large-scale national survey in China. In conclusion, the implications for policy development and nonprofits’ work in social participation mobilization are discussed.

\section{Social Participation and “Value-oriented” Mobilization}

\section{The concept of social participation}

Social participation is subject to a variety of interpretations. Hodge and Treiman (1968) considered a range of dimensions, including voluntary memberships, church attendance, and informal association with friends. Most subsequent studies have similarly focused on association membership as a proxy for social participation (Parker, 1983). Social participation often occurs through the mediating agency of personal networks, as well as through formal and informal organizations (Krishna 2002). These organizations exist in various forms, but share common features: they are non-profit, non-governmental, and voluntary (Salamon et al. 1999). Tomeh (1973) cited a range of measures of social participation, including the number of association affiliations, frequency of attendance, length of membership, and time invested in association meetings and leadership activities. Auslander and Litwin (1988) employed the Group Participation Index that included participation in a labor union, commercial group or professional organization; a church-related group; a group concerned with children (such as 
Boy/Girl Scouts); a community betterment, charity or service organization; and/or any other group that is mainly social, fraternal or recreational.

More recently, Douglas and colleagues (2017) frame social participation as either informal social participation or social engagement, which includes activities that people engage in with others for personal enjoyment; formal social participation or civic engagement, includes activities that people engage in for the benefit of others to whom they owe no obligation. There are then two types of social participation. The first is mutual-benefit or member-enjoyment/interest orientated participation, such as involvement in leisure and entertainment clubs, saloons or townsmen associations. The second is for public-benefit, such as involving in philanthropic organizations and social work institutions.

\section{The features of social participation and mobilization in China}

This study considers two approaches to social participation mobilization: instrumental mobilization and value-oriented mobilization. According to Weber's (1978) delineation of value rationality and instrumental rationality, instrumental mobilization focuses on the means of social participation, while value-oriented mobilization focuses on the objectives of social participation.

Although people's well-being is a stated priority, in practice, the government chooses to follow the logic of instrumental rationality and often makes risk control and bureaucratism the goals of social participation. Participants' wellbeing may be promoted to some degree in the process, but there has been no measurable increase in civil society as a result. In order to control risk, China's instrumental mobilization avoids empowering individuals and communities to initiate 
social change or to challenge governmental authority (Huang and Ji 2016). Instead, the state endeavors to mobilize the public to engage in specific social service programs so that government performance goals are met; the focus is often on the scale and output of initiatives rather than their efficacy and impacts (Xu 2007).

As an alternative approach, value-oriented mobilization focuses on what participants actually value. Because it is people focused, a value-oriented social participation project is more likely to be sustainable. It also follows the logic of value rationality, emphasizing the ultimate purpose of social participation. At the micro-level, it is meant to meet people's emotional and psychological needs. At the macro-level, it is meant to benefit a broad range of people. Both levels will be examined in the following sections. Likewise, there are two essential elements of value-oriented mobilization. This first is to create a value proposition that promotes individuals' happiness. The second element is attracting marginalized members of society by offering programs that prioritize their needs and aspirations.

China's social mobilization, in practice, is not value-oriented. One example of this observation is the state's over-reliance on altruism. As revealed in government documents, official statements, and news reports, the state most frequently tries to motivate citizen engagement in poverty alleviation that is not necessarily directly related to the target participants' direct interests or well-being (Xu 2007). That is a crucial disconnect. The mobilization of social participation is a dyadic process that will become less effective if the likely motivations and preferences of participants are not taken into consideration. Another example is the effort to enrich citizens' spiritual and cultural lives by promoting entertainment activities, such as 
square dances and art classes. Many of the most disadvantaged social groups, such as migrants and people with disabilities, face significant barriers to accessing such opportunities.

As the current instrumental mobilization approach does not appear effective, it seems to have been assumed that the public is not significantly active in social participation in China. However, none of the previous studies have revealed the features of social participation in China. This study will examine the overall rate, frequency, and diversity of social participation based on an analysis of national survey data.

\section{Towards the Value-oriented Mobilization of Social Participation}

As discussed previously, this article advocates for the adoption of value-oriented mobilization in China. This leads to some essential questions. At the micro-level: in what ways does social participation impact individuals' happiness, and how best to use this function of social participation in the mobilization process? At the macro-level: is there a segmentation of social participation between different social groups such as migrants and local residents in urban China, and by what means might it be possible to improve the inclusiveness of social participation?

\section{Ways to promote happiness}

People's happiness is a clearly stated goal of the Chinese government. At the $19^{\text {th }}$ Communist Party of China National Congress in October 2017, General Secretary, Xi Jinping reiterated that "the original aspiration and the mission of Chinese Communists is to seek happiness for the Chinese people and rejuvenation for the Chinese nation” (China Daily 2017). People’s 
happiness is consistently declared as the premise, value pursuit, and foundation of good governance. However, according to World Values Survey data (Easterlin et al. 2010), China has suffered a significant decrease in happiness over the past two decades. This seems to be the government's impetus for generating greater levels of happiness.

As a public good, social participation is mainly premised on the benefits that it brings to individuals' happiness and quality of life (Lee et al. 2007). Before examining the correlates, it is important to note that one issue that has plagued studies on "happiness" is the conceptualization of happiness itself. The definition of happiness varies in the literature and lacks a clear and consistent definition and, as such, it can convey multiple meanings (Mazhari 2015). Many scholars have defined happiness as a psychological concept which contains components reflecting a person's life experiences, and their judgments about life as a whole (Diener 2000; Seligman 2002; Kahneman 1999; Easterlin 1974; Seligman and Csikszentmihalyi 2000). Conceptualization only serves to attract more confusion when researchers homogenize "happiness" with other terms. For instance, happiness is often overlapped with "well-being”, of which one of the key domains is life satisfaction (Diener and Seligman, 2004).

Empirically, the operational definition of happiness is all too often inexact and inconsistent. Phillips $(1967,1969)$ measured self-reported happiness directly using an item: “Taking all things together, how would you say things are these days- would you say you are very happy, pretty happy, or not too happy?” Some researchers have defined happiness as the feeling of overall life satisfaction, and this has been measured by deploying a questionnaire item based on 
a 10-point scale: “All things considered, how satisfied are you with your life as a whole these days?” (e.g. Mazhari 2015). In addition, some psychologists have suggested that happiness should be measured across multiple items reflecting its various aspects (e.g., pleasant emotions, engagement, and finding meaning and purpose in life; or life satisfaction, positive affect, and negative affect), and that it be assessed by multiple methods (Seligman 2002; Lucas et al. 1996).

In this study, we did not systematically investigate the various aspects of happiness in each domain. Not only would this be beyond the scope of this research, but rarely have studies engaged with such a broad set of measures. For the purposes of this article, as with Easterlin (2004, p.26), we refer to happiness as interchangeable with life satisfaction, in the sense of it being an overall sense of subjective well-being. Moreover, self-reported happiness is also considered as a straightforward indicator of individuals' level of happiness, as suggested by Phillips $(1967,1969)$. Therefore, we employed two indicators to reflect individuals’ overall level of happiness: overall life satisfaction and self-reported happiness.

There is solid evidence of a link between social participation and happiness (Barker 2011). For instance, Phillips (1967) reports on a study demonstrating that self-reports of happiness are strongly related to the extent of social participation. Putnam (2000) also related similar relationships. Social scientists have consistently identified the role of social participation in promoting happiness. For example, social activities involving recreation and exercise enhance both individuals’ physical and psychological health (Cacioppo et al. 2006). 
Pursuing a good and meaningful life through social participation has been identified as a means to promote happiness (Seligman 2002, 2011). Positive roles in social activities, such as community service and volunteering, shape one's identity and self-worth, and thus contribute to greater levels of general well-being (Thoits and Hewitt 2001). Again, it has been argued that the process brings emotional benefits and the generation of a general sense of well-being (Zhang and Zhang 2015). Happiness studies suggest that helping others is major source of life meaning and happiness (Ehrenreich 2009). Researchers such as Frey (2008) also found that those who volunteer on a regular basis report being happier and of better health than those who do not volunteer. Thus, social participation, such as voluntary and charitable activities, can promote happiness through altruism and self-actualization.

Moreover, social participation encourages healthy interaction and the building of networks and social bonds which, again, are associated with happiness (Putnam 2000; Nieminen et al. 2010; Berkman et al. 2000; Fowler and Christakis 2008; Hsu and Chang 2015). It has been consistently found that happier people have stronger family and social networks (i.e. Diener and Seligman 2004). Davidson and Cotter (1991) also reveal a correlation between a sense of community and happiness. Social participation, such as community organization activity, facilitates a sense of community and belonging, as well as strong emotional bonding and investment in the group, and as such, it promotes the generation of happiness.

Apart from the frequency of social participation, the diversity of social participation is also linked to happiness. Howell et al. (2011) and Rasskazova et al. (2016) found that the greater the variety of an individual's social participation, the higher the possibility that the individual's 
multiple needs will be fulfilled, which would bring more happiness. In other words, an individual could obtain a higher state of happiness if their needs were better met through a greater diversity of social participation.

Putnam's seminal study (2000) linked social participation to the development of social networks and social capital, and hence, he argued, to happiness. In addition to needs fulfillment, social participation could produce positive outcomes across a range of social indices and thereby make a considerable contribution to both individual and collective happiness. As Putnam suggested, the increasing abundance of social participation facilitates the accumulation of social connections and helps to broaden social circles. Involvement in a residential community committee or a property owners' committee may extend beyond the limit of blood and geographical relationships and help to build connections with people who share similar rights consciousness and interests. Involvement in philanthropic or voluntary organizations and social work institutions will inevitably connect individuals who share the same values. Thus, the greater the diversity of social participation one engages in, the broader one’s social network will be, the more social support one will perceive, and the greater the happiness one will obtain. Consequently, we proposed two hypotheses: First, the higher the frequency of social participation, the higher the state of happiness an individual can obtain (H1). Second, the diversity of an individual's social participation is positively related to their level of happiness (H2). 


\section{The imperative of improving the inclusiveness of social participation}

China's dramatic transformation over the last four decades has included impressive economic growth, widespread population mobility, and greater economic and social freedoms (Han 2015). This makes it a particularly suitable setting for a study on social participation. Urbanization on such an unprecedented scale has contributed to a diversity of social participation across systematically segmented groups. This process continues apace and it clearly has implications for both social policy and governance.

As China's population has become increasingly mobile, citizens can be identified as local or nonlocal based on their hukou status. In mainland China, hukou is the legally required governmental record of an individual's household registration from birth. It acts as a control on population mobility by advantaging local people, to varying extents, in the entitlement to public services, such as labor protection, medical care, children’s education, and social insurance.

Because of its entrenchment in the social strata, especially as between rural and urban citizens, and those with local and nonlocal residency status, the hukou system is often regarded as a form of social closure, by which groups maintain their resources and status to the exclusion of others (Wu and Treiman 2004).

Given their circumstances, migrants would appear to have sufficient motivation to engage in social participation. The absence of effective public policy under the hukou system to protect their welfare, combined with the lack of existing emotional bonds in a new, often alien, and unfamiliar place, suggests that the ability to broaden and enhance their social networks would be of considerable benefit . The act of engaging in social networks could both facilitate their 
social integration and alleviate their feelings of alienation and isolation (Chan and Zhang 1999).

Whilst the state has made some efforts, at least superficially, to partly incorporate migrant workers into urban communities (Palmer, Perkins and Xu 2011), migrants, particularly those from rural areas, continue to be more disadvantaged than local people when attempting to become involved in community activities or political participation; partly because they are too isolated, insecure and socially disoriented, and partly because most of them are not encouraged to do so (Palmer, Perkins and Xu 2011). Liu (2005) points to the social and economic disadvantages of migrants without urban local hukou status. They usually have fewer years of education, are less likely to have a state sector job and employer-provided healthcare benefits, and are more likely to be self-employed or unemployed and earning lower incomes-because both the state sector and private firms often only hire local residents (Liu 2005, p.133).

Consequently, we tested two hypotheses. First, migrants have a lower level of social participation than local residents in urban China, both in terms of frequency and diversity (H3). Second, migrants from rural areas have a lower level of social participation than migrants from urban areas, both in terms of frequency and diversity (H4).

\section{Research Methodology}

\section{Introduction of data}

Data from the China Labor-force Dynamics Survey (also known as CLDS) was collected and analyzed for this study. CLDS is a national, large scale, interdisciplinary, biennial survey 
undertaken in China by Sun Yat-sen University since 2012. It is a secondary data methodology widely used for research purposes especially in China. The survey covers a range of labor-related issues, including education, economic and employment status, migration status, and social participation. The survey's sampling methods include multistage cluster, stratified, and probability proportional to size (PPS) sampling.

Data from the 2016 CLDS was used in this study as follows. The total population of China (excluding Hong Kong, Macao, Taiwan, Tibet, and Hainan) served as the initial sample frame, which was then divided into separate groups according to the population scale of the different provinces located in the eastern, middle, and western areas of China. Village committees and urban residents’ committees within each group were then selected using PPS; this constitutes the second sample frame. Finally, households were randomly selected within the village committees and urban residents' committees, with all residents aged above 15 years being included in the sample. In total, the study sample included 4510 urban dwellers aged between 17 and 80 years.

\section{Variables}

Social participation

Social participation was measured in the CLDS with the following survey questions. "Have you been a member of the following organizations in the past year?” ${ }^{3}$ The social organizations considered were: (1) learning/training institution, (2) leisure/entertainment/sport club/saloon, (3) townsmen association, (4) clan association, (5) residential community committee, (6) property owners’ committee, (7) philanthropic/voluntary organization, (8) 
social work institution, and (9) religious organization. Of these, engaging in philanthropic/voluntary organizations and social work institutions were held to be public-benefit oriented social participation, whilst the other categories were mutual-benefit oriented social participation. As this is a multiple-choice question, we measured diversity of social participation by the total number of association affiliations. Regarding the frequency of social participation, a five-point-scale (from 0 to 4 ) was provided for the respondent to rate "How frequently did you participate in their activities over the past twelve months": never (“0”), rarely (“1”), sometimes (“2”), often (“3”), and always (“4”).

\section{Happiness}

As mentioned previously, we used two indicators to reflect individuals’ overall level of happiness: overall life satisfaction and self-reported happiness. Overall life satisfaction was measured with the following survey item: “Are you satisfied with your life overall?” Options ranged from 1 ("very unsatisfied”) to 5 (“very satisfied”). Self-reported happiness was measured with the item: “Generally speaking, do you live a happy life now?” Options ranged from 1 (“very unhappy”) to 5 (“very happy”).

\section{Other variables}

Some relevant variables were considered when analyzing associations between social participation and happiness. They were: (1) Gender: many studies have found that in Asian countries females signify a higher level of happiness than do males (e.g., Helliwell and Putnam 2004). (2) Age: there is a general U-shaped pattern between age and happiness (e.g., Helliwell 2006). (3) Income: income has shown a positive correlation with happiness (Diener 
et al. 1999). (4) Health: poor physical health significantly depresses reported happiness (e.g., Winkelmann and Winkelmann1998). (5) Education: the typical happy person is well-educated (Wilson 1967). (6) Social support: social support is helpful for the fulfillment of attachment, esteem, social approval, belongingness, and social identity, which greatly contribute to happiness (Takagi, Kondo and Kawachi 2013). (7) Hukou (rural and urban hukou), and (8) mobility (local resident and migrant): migrants without local urban hukou have a significantly lower level of happiness than local residents in both cities and rural areas due in part to the impact of income inequality (Jiang, Lu and Sato 2012).

Among the above control variables, income was estimated by the logarithm of the annual income in regression models. Self-rated physical health was measured using a five-point-scale response from very unhealthy (coded as 1) to very healthy (coded as 5). Hukou was a dummy variable which had two values: urban (coded as 1) and rural (coded as 0). Mobility was defined based on hukou status, and was coded as "0" (migrant) when the individual had not lived in the place of their hukou registration for more than six months, otherwise it was coded as “1” (local). Education level was measured in terms of years of formal education with options from 3 (no formal education) to 22 (Ph.D.). Gender was a dummy variable including two values: female coded as 0 and male coded as 1 . Social support was measured with the item "How many close friends do you have that are capable of offering support and help in the city/village where you live?” Methods of data analysis included descriptive analysis, one-way ANOVA, and linear regression analysis. 
Based on the 2016 CLDS, the mean score of self-reported happiness and life satisfaction were 3.87 and 3.77, respectively, which indicates that respondents tended to be happy on average (see Table 1). Among the respondents, $54.15 \%$ were males and $45.85 \%$ were females; the average number of close friends they had was 10, with a high degree of variation; the average score of self-reported health was 3.88; the average age of respondents was 41 years; and, the average annual income was 51752.45 RMB. Among the sample, local residents accounted for $81.60 \%$, and people with urban hukou accounted for $62.79 \%$. The mean score for length of education was 11.63 years, indicating respondents had a middle level of education on average.

[Insert Table 1]

\section{Analysis Results}

\section{Patterns of social participation in China}

Table 2 shows that the overall rate of social participation in urban China at the time of the survey was low, as was the rate of different forms of social participation. In the past year, only $15.83 \%$ of respondents were engaged in some form of social participation. Among the different forms of social participation, the rate of engaging in the activities of a residential community committee was the highest (6.61\%), followed by those of a learning/training institution (4.17\%) and a leisure/entertainment/sports club and saloon (3.08\%). The percentage of respondents who engaged in a clan association or religious organization was the 
lowest, accounting for $0.55 \%$ and $0.80 \%$, respectively. Among participants, the average frequency of social participation in the previous year was 3.43 ( $S D=2.12$, range from 1 to 14 ). In other words, most participants only "rarely" or "sometimes" participated in those organizational activities. The average number of association affiliations was $1.36(S D=0.73)$. Overall, survey respondents were not particularly active in programming initiated by social organizations. For those respondents who did participate, most only engaged infrequently in one social organization. Additionally, respondents tended to engage in mutual-benefit social participation rather than public-benefit social participation.

[Insert Table 2]

\section{The association between social participation and happiness}

Results from multiple linear regression analysis (in Table 3-1) show that, with the exception of age and urban-rural hukou status, all control variables significantly affected urban dwellers' self-reported happiness in China (see Model 1). Females were more likely to feel a higher level of happiness. People who obtained a higher level of income, education, or social support tended to have a higher level of happiness. People who reported better health also had a higher level of happiness. In contrast with local residents, migrants were more likely to have a lower level of self-reported happiness.

The results support our hypotheses $\mathrm{H} 1$ and $\mathrm{H} 2$. When controlling for the above variables, frequency of social participation significantly influenced individuals’ self-reported happiness. 
Model 2 reveals that happiness increased by an average of 0.06 when the frequency of social participation increased 1 unit. Additionally, diversity of social participation significantly affected individuals' self-reported happiness when demographic variables were controlled. Model 3 shows that happiness increased by an average of 0.07 when the category of social participation increased 1 unit. A similar correlation between social participation and life satisfaction is also shown in Table 3-2.

[Insert Table 3-1]

[Insert Table 3-2]

\section{Migration, hukou gaps, and social participation}

The regression results also support hypotheses H3 and H4. Table 4 reveals a lower level of social participation, both in terms of diversity and overall frequency, for migrants in comparison with local residents. The difference in diversity of social participation between the two groups was statistically significant $(F=7.19, p<0.01)$. In other words, migrants were less active than local residents in social participation in China. After further categorizing respondents based on their mobility and hukou status, we found that migrants with rural hukou had the lowest level of social participation, while migrants with urban hukou had the 
highest level of social participation, both in terms of overall frequency $(F=10.13, p<0.001)$ and diversity $(F=12.25, p<0.001)$. That represents a significant difference in engagement amongst migrants.

The disparity in social participation was also obvious between those residents who held rural hukou and those who held urban hukou. Respondents with rural hukou had a significantly lower level of social participation than those with urban hukou, both in terms of overall frequency $(F=27.18, p<0.001)$ and diversity $(F=33.43, p<0.001)$. Moreover, among local residents, those with urban hukou were significantly more active in social participation activities than those with rural hukou, both in terms of overall frequency $(F=12.99, p<0.001)$ and diversity $(F=15.02, p<0.001)$. It should be noted that some local residents of an urban area may have rural hukou. This group of people usually comes from rural villages that were incorporated into rapidly urbanizing cities (cheng zhong cun).

[Insert Table 4 here]

\section{Findings and Discussion}

\section{Popularity of social participation in China}

Over the one-year time period considered in this study, the overall rate of social participation was low, as was the participation rate in different forms of social activities. Survey respondents indicated limited engagement in social participation. Few respondents had been members of more than one type of social organization in the previous year; and, most respondents only 
"rarely" or "sometimes” participated in those organizational activities. In addition, respondents were more likely to engage in mutual-benefit social participation rather than the public-benefit variety. Understandably, mainland China had a considerably lower rate of citizen engagement with organized religion compared to western countries.

Furthermore, many economically developed western countries have a civil society with deep historical roots. China’s social history is considerably different. Four decades of rapid urbanization have produced an economic miracle, but the rate of social participation in China remains a relatively low public priority. As highlighted in this study’s findings, the considerable official efforts to motivate social participation have been neither effective nor productive. In China, the government continues to play a dominant role in organizing people to participate in various social activities, including social movements and volunteer activities (He 2010). Given the huge mismatch between effort and result, this study suggests that the current instrumental mobilization approach should be replaced with the more inclusive form of value-oriented mobilization illustrated below.

\section{Happiness and value-oriented mobilization}

As the study's findings reveal, respondents who engaged in social participation were more likely to report a significantly higher level of happiness. The diversity of an individual's social participation was also an important factor of happiness. Along with needs fulfillment, an increasing abundance of opportunities for social participation will contribute to the process of accumulation of social capital and social networks, and this again, impacts an individual's 
happiness. In short, diverse avenues for engagement, in addition to the frequency of social participation, can promote happiness in China's urban residents.

However, current efforts to simultaneously facilitate and harness social participation in mainland China have failed to foster the conditions conducive to the generation of happiness. This study’s findings reveal that respondents were more likely to engage in mutual-benefit social participation than they were in public-benefit social participation. However, governmental mobilizations focus on participation in poverty alleviation that is not necessarily directly related to participants’ interests or well-being (Xu 2007). There is no clear link between this activity and participants' happiness. Thus, although the government has declared that people's happiness is the key to people-oriented governance, and that it plays a central role in good governance, the generation of social participation to promote people's happiness has not yet been afforded sufficient priority.

The function of social participation in promoting happiness is also hindered by the limited number of outlets that can fulfill residents' aspirations for social participation in today's China. The most popular form of social participation, the residential community committee, largely fails to achieve its self-governance function as the mechanisms for deliberative governance in urban communities remain underdeveloped (Tang 2015). These institutions can hardly be expected to meet or facilitate the general population's need to exercise civil rights as fully engaged citizens and thereby allow them to obtain social respect and happiness. Attendance at a learning or training institution is another popular form of social participation but, again, this is 
limited by insufficient resources and support for the not-for-profit institutions organizing such activities ( $\mathrm{Lu} 2003)$.

In direct contrast to traditional top-down social initiatives, the government and policymakers should encourage local communities to set social agendas according to their own perception of individual and communal interest. That sense of ownership can only serve to further encourage greater levels of engagement and participation. That is the very essence of value-oriented participation. To encourage individuals to actively engage in social participation, governments and social organizations should begin by improving their capacity to mobilize residents. For example, the primary goal of a residential community committee’s social participation mobilization program should be to get residents involved. If skills training was offered to improve residents' self-governance abilities, and ongoing support was provided by social organizations or the government, then residents would likely feel empowered to participate in committee activities. The problem with this suggestion is that it takes time and resources and may require incremental changes in power relationships. But mighty oaks from little acorns grow. Social organizations and governments can aid the growth process by actively collaborating to develop a not-for-profit infrastructure of knowledge sharing. Social organizations should also be encouraged to organize collaborative activities that are in the interest of the greater good.

\section{Inclusiveness and value-oriented mobilization}

Regarding the second element of value-oriented mobilization, the study's findings reveal that social participation varied across systematically segmented groups. There were stark 
differences in social participation between local residents and migrants in urban China. Levels of social participation also varied between different migrant communities. Migrants with urban hukou had the highest level of social participation, both in terms of overall frequency and diversity. However, for migrants with rural hukou, it was a very different picture. There was a far lower rate of social participation among this group.

Social participation is of great importance for migrants. It can assist them in building and broadening their social networks, it can also serve as a motor for social integration and the building of a "harmonious society" (he xie she hui). Mobilizing social participation among migrants in urban China, especially those with rural hukou, would likely improve their well-being. There remain significant barriers to this, politically and socially, but these should not be considered insurmountable (Palmer, Perkins and Xu 2011).

Although large-scale mobility and rapid urbanization have brought many social problems to China's cities, the welfare of migrants who greatly contributed to city construction projects should still be protected. In the first instance, the government should attend to the gaps in welfare services for migrants. They should have access to essential public services equal to those of local residents. Inevitably, this would greatly contribute to their sense of security and, thus, assist and encourage them to engage in broader social activities. It would also create communities of interest with local citizens who benefit from the same services.

For their part, existing social organizations should be encouraged to incorporate migrants and other disadvantaged groups into their existing activities. That process could be facilitated by a range of fiscal incentives, in much the same way Western governments have provided 
additional support for the marginalized generally and migrants in particular. For instance, in the EU, the 2016 Action Plan for the European Union’s Policy Framework for Migrant Integration stated as its policy goal to provide “a comprehensive framework to support Member States' efforts in developing and strengthening their migrant integration policies” (European Commission 2016). At the individual state level this has been translated into a plethora of national, regional, and local initiatives to support migrant workers into education, employment, and community projects; for instance, in the UK, the City of Coventry's MiFRIENDLY CITIES project, which brings together initiatives to encourage employment, meet health needs, and encourage active citizenship (Wolkowinski 2018). It is certainly clear that such initiatives can be crucial in both encouraging integration and promoting a general sense of well-being (Hickman, Crowley and Mai 2008). Similarly, policymakers in China should develop socially inclusive programs to further encourage and support migrants who want to participate in a city’s social life.

\section{Conclusion}

Despite official mobilization initiatives, the popularity of social participation in mainland China remains low; migrants, in particular, are excluded from key activities; and, the function of social participation, to promote happiness, is not the focus of current mobilization practices. Greater levels of social participation and more inclusive forms of participation are possible. But, in order to include the most disadvantaged and disenfranchised citizens, both government and nonprofits must consider participants' interests and motivations and transform mobilization from an instrumental to a value-oriented process. 
However, completing this transformation will mean re-thinking the government's role in civil society engagement. In short, the state shapes and restricts civil society engagement both in the political space and in the social space. Furthermore, the top-down mobilizations preferred by the Chinese state entail huge disconnects between the state as mobilizer and the social engagement participants. Instead, as advocated in this paper, value should be placed on the agency exercised from below by civil society actors themselves. This is possible. Due to the social problems caused by China's rapid economic development, social organizations or non-profits sprang in to being because the party-state became less omnipresent, and new spaces for civil society engagement developed. What must be accepted in the Chinese political context is that civil society space goes through cycles of contraction and expansion. Currently, and since the leadership change in the end of 2012, the regulation of social organizations and civic engagement has become gradually heavier. The space for civil society is currently cycling through its contraction phase.

In the push to promote social participation, along with the shift from instrumental to value-oriented mobilization by the state, the social organization should become the essential civil society actor and play a more positive role. In this period of increased constraints on political space, instead of focusing engagement on politically sensitive and potentially subversive practices, social organizations concentrate on practices seen as politically insignificant or apolitical. One strategy is to blur the boundary between the political and the apolitical, and avoid those practices that could be conceived as either entirely apolitical or entirely political. Within an authoritarian political context, the party-state is more open to accept engagement which it deems social rather than political. Such activism has been greatly 
encouraged and state-civil society relations are framed as a partnership, in which civil society can provide services that are beyond the capacity of the state such as community services and skills training. Social organizations should promote dialogue between the state and civil society and precisely identify the needs that social participation can help fulfil.

\section{Notes}

\footnotetext{
1 According to the Sixth National Population Census of China, there were 261,386,075 internal migrants within China.

2 Please see the official website of China Labor-force Dynamics Survey http://css.sysu.edu.cn

3 This question was asked among urban dwellers in mainland China.
}

\section{Acknowledgement}

We would like to thank the editors of this journal and the two anonymous reviewers for many helpful comments and constructive suggestions. This study was funded by The National Social Science Fund of China (NSSFC) (17CSH061). The authors declare that they have no conflict of interest.

\section{References}

Abatena, H. (1997). The significance of planned community participation in problem solvingand developing a viable community capability. Journal of Community Practice, $4(2), 13-34$.

Auslander, G. K., \& Litwin, H. (1988). Sociability and patterns of participation: implications for social service policy. Nonprofit \& Voluntary Sector Quarterly, 17(2), 25-37. 
Barker, C. J. \& Martin, B. (2011). Participation: the happiness connection. Journal of Public Deliberation, 7 (1), 1-16.

Baker, L. A., Cahalin, L. P., Gerst, K., \& Burr, J. A. (2005). Productive activities and subjective well-being among older adults: The influence of number of activities. Social Indicators Research, 73(3), 431-458.

Berkman, L. F., Glass, T., Brissette, I., \& Seeman, T. E. (2000). From social integration to health: Durkheim in the new millennium. Social Science and Medicine, 51(5), 843-857.

Cacioppo, J., Hughes, M., Waite, L., Hawkley, L., \&Thisted, R. (2006). Loneliness as a specific risk factor for depressive symptoms: Cross-sectional and longitudinal analyses. Psychology and Aging, 21 (1),140-151.

Chan, K., \& Zhang, L. (1999). The hukou system and rural-urban migration in China: Processes and changes. The China Quarterly, 160, 818-855.

China Daily. (2017). Xi Jinping delivers report to CPC congress. China Daily, 2017-10-18. http://usa.chinadaily.com.cn/china/2017-10/18/content_33398861.htm.Accessed 02 January 2018.

Cicognani, E., Pirini, C., Keyes, C., Joshanloo, M., Rostami, R., \&Nosratabadi, M. (2008). Social participation, sense of community and social well-being: a study on American, Italian and Iranian university students. Social Indicators Research, 89(1), 97-112.

Davidson, W. B., \& Cotter, P. R. (1991). The relationship between sense of community and subjective well-being: A first look. Journal of Community Psychology, 19(3), 246-53.

Diener, E. (2000). Subjective well-being: The science of happiness, and a proposal for a national index. American Psychologist, 55(1), 34-43. 
Diener, E., \& Seligman, M. E. P. (2004). Beyond money: Toward an economy of well-being. Psychological Science in the Public Interest, 5(1), 1-31.

Diener, E., Suh,E., Lucas, R.E. \& Smith, H.L. (1999). Subjective well-being: Three decades of progress. Psychological Bulletin, 125 (2), 276-302.

Douglas, H., Georgiou, A., \& Westbrook, J. (2017). Social participation as an indicator of successful aging: An overview of concepts and their associations with health. Australian Health Review, 41, 455-462.

Easterlin, R.A. (1974). Does economic growth improve the human lot? Some empirical evidence. In P.A. David \& W.R. Melvin (Eds.), Nations and households in economic growth (pp. 98-125). Palo Alto, CA: Stamford University Press.

Easterlin, R. A. (2004). The Economics of Happiness. Daedalus, 133 (2), 26 - 33.

Easterlin, R. A., McVey, L. A., Switek,M., Sawangfa, O., \& Zweig, J. S. (2010). The happiness-income paradox revisited. Proceedings of the National Academy of Sciences of the United States of America, 107(52), 22463-22468

European Commission (2016). Action Plan on the integration of third country nationals. https://ec.europa.eu/home-affairs/sites/homeaffairs/files/what-we-do/policies/european-a genda-migration/proposal-implementation-package/docs/20160607/communication_acti on_plan_integration_third-country_nationals_en.pdf. Accessed 2 February 2019.

Ehrenreich, B. (2009). Bright-sided: How the relentless promotion of positive thinking has undermined America. New York: Metropolitan Books.

Frey, B. (2008). Happiness: A revolution in economics. London, England: MIT Press. 
Fowler, J. H., \& Christakis, N. A. (2008). Dynamic spread of happiness in a large social network: Longitudinal analysis over 20 years in the Framingham Heart Study. British Medical Journal, 337, 23-38.

Han, C. (2015). Explaining the subjective well-being of urban and rural Chinese: income, personal concerns, and societal evaluations. Social Science Research, 49, 179-190.

He, L. (2010). Still the age of the state? organized social participation and civil society development in urban china. Pacific Focus, 24(3), 317-340.

Helliwell, J. F. (2006). Well-being, social capital and public policy: What's new? The Economic Journal, 116 (510), C34-C45.

Helliwell, J.F. \& Putnam, R. (2004). The social context of well-being. Philosophical Transactions of the Royal Society London, 359 (1449), 1435-1446.

Hickman, M., Crowley, H., \& Mai. N. (2008) Immigration and social cohesion in the UK: The rhythms and realities of everyday life. Joseph Rowntree Foundation.

Hodge, R. W., \&Treiman, D. J. (1968). Social participation and social status. American Sociological Review, 33(5), 722-740.

Howell, R.T., Chenot, D., Hill. G., \& Howell, C. J. (2011). Momentary happiness: The role of psychological need satisfaction. Journal of Happiness Studies, 12 (1), 1-15.

Hsu, H., \& Chang, W. (2015). Social connections and happiness among the elder population of Taiwan. Aging and Mental Health, 19 (12), 1-7.

$\mathrm{Hu}$, A. (2014). Social participation, types of trust, and subjective well-being: Investigation based on CGSS 2005 (shehuicanyu, xinrenleixingyujingshenjiankang: jiyu CGSS2005 de kaocha). Journal of Social Sciences (ShehuiKexue), 4, 64-72. (In Chinese). 
Huang X., \& Ji X. (2016). Limits to micromanagement and logic of the reform (jishuzhili de jixianjiqichaoyue). Journal of Social Sciences (ShehuiKexue), 11, 73-79. (in Chinese).

Jiang, S., Lu, M., \& Sato, H. (2012). Identity, inequality, and happiness: Evidence from urban China. World Development, 40(6), 1190-1200.

Kahneman, D. (1999). Objective happiness. In: Kahneman, D., Diener, E., Schwarz, N. (Eds.), Well-being: The foundations of hedonic psychology (pp.3-25). New York: Russell Sage.

Krishna, A. (2002). Enhancing political participation in democracies: What is the role of social capital? Comparative Political Studies, 35, 437-460.

Lee, H. Y., Jang, S. N., Lee, S., Cho, S. I., \& Park, E. O. (2008). The relationship between social participation and self-rated health by sex and age: A cross-sectional survey. International Journal of Nursing Studies, 45(7), 1042-1054.

Lindström, M., Merlo, J., \& Östergren, P. (2002). Individual and neighborhood determinants of social participation and social capital: A multilevel analysis of the city of Malmö, Sweden. Social Science \& Medicine. 54 (12), 1779-1791.

Liu, Z. (2005). Institution and inequality: The hukou system in China. Journal of Comparative Economics.33 (1), 133-157.

Lu, Y. (2003). The limitations of NGOs: A preliminary study of non-governmental social welfare organisations in China. LSE Research Online Documents on Economics 29218, London School of Economics and Political Science, LSE Library.

Lucas, R.E., Diener, E., \& Suh, E.M. (1996). Discriminant validity of well-being measures. Journal of Personality and Social Psychology, 71, 616-628. 
Mazhari, L (2015). The Pursuit of Happiness: The Effect of Social Involvement on Life Satisfaction in Canada. The Arbutus Review, 6 (1), 76-100.

Nieminen, T., Martelin, T., Koskinen, S., Aro, H., Alanen, E., \&Hyyppä, M. (2010). Social capital as a determinant of self-rated health and psychological well-being. International Journal of Public Health, 55 (6), 531-542.

Nummela, O., Sulander, T., Rahkonen, O., Karisto, A., \&Uutela, A. (2008). Social participation, trust and self-rated health: A study among aging people in urban, semi-urban and rural settings. Health \& Place, 14 (02), 243-253.

Olsen, M. E. (1972). Social participation and voting turnout: A multivariate analysis. American Sociological Review, 37(3), 317-333.

Parker, R. N. (1983). Measuring social participation. American Sociological Review, 48(6), 864-873.

Palmer, N. A., Perkins, D. D., \& Xu, Q. (2011). Social capital and community participation among migrant workers in China. Journal of Community Psychology, 39(1), 89-105.

Phillips, D. L. (1967). Social participation and happiness. American Journal of Sociology, 72(5), 479-488.

Phillips, D. L. (1969). Social class, social participation, and happiness: A consideration of “interaction-opportunities” and “investment”. The Sociological Quarterly, 10 (1), pp. $3-21$

Plummer, J., \& Taylor, J. G. (2004). Community participation in China: Issues and processes for capacity building. VA: Earthscan. 
Prohaska, T. R., Anderson, L. A., \& Binstock, R. H. (Eds). (2012). Public Health for an Aging Society. Baltimore, MD: John Hopkins University Press.

Putnam R.D. (2000). Bowling alone: The collapse and Revival of American Community. New York: Simon \& Schuster.

Rasskazova, E., Ivanova, T., \& Sheldon, K. (2016). Comparing the effects of low-level and high-level worker need-satisfaction: A synthesis of the self-determination and Maslow need theories. Motivation and Emotion, 40 (4), 541-555.

Salamon, L. M., Anheier, H. K., List, R., Toepler, S., \& Sokolowski, S.W. (1999). Global civil society: Dimensions of the nonprofit sector. Baltimore: Johns Hopkins Center for Civil Society Studies.

Seligman, M. E. P. (2002). Authentic Happiness: Using the new positive psychology to realize your potential for lasting fulfillment. New York: Free Press.

Seligman, M. E. P. (2011). Flourish: A visionary new understanding of happiness and well-being. New York: Free Press.

Seligman, M.E.P., \& Csikszentmihalyi, M. (2000). Positive psychology. American Psychologist, 55 (1): 5-14.

Sewell, H. W. (1978). Social mobility and social participation. Annals of the American Academy of Political \& Social Science, 435(1), 226-242.

Takagi, D., Kondo, K., \& Kawachi, I. (2013). Social participation and mental health: Moderating effects of gender, social role and rurality. BMC Public Health, 13 (1), 701-723. 
Tang, B. (2015). Deliberating governance in Chinese urban communities. The China Journal, 73: 84-107.

Taylor. P.(2010). Age Equality in Education and Training, in Penelope Peterson, Eva Baker and Barry McGaw (eds), International Encyclopedia of Education (Third Edition). Oxford, England: Elsevier.

The State Council Information Office. (2016). China’s Progress in Poverty Reduction and Human Rights. Xinhuanet, 2016-10-17.

http://news.xinhuanet.com/english/china/2016-10/17/c_135760210.htm. Accessed 02 January 2018.

Thomas, P. A. (2011). Gender, social engagement, and limitations in late life. Social Science \& Medicine,73(9), 1428-1435.

Thoits, P. A., \& Hewitt, L. N. (2001). Volunteer work and well-being. Journal of Health and Social Behavior, 42(2), 115-131.

Tomeh, K. A. (1973). Formal voluntary organizations: Participation, correlates and interrelationships. Sociological Inquiry, 43, 89-110.

Weber, M. (1978). Economy and Society. University of California Press.

West, A. (2007). From performance to practice: Changing the meaning of child participation in china. Children Youth \& Environments, 17(1), 14-32.

Wilson, W. (1967). Correlates of avowed happiness. Psychological Bulletin, 67, 294-306.

Winkelmann, L., \& Winkelmann, R. (1998). Why are the unemployed so unhappy? Evidence from panel data. Economica, 65, 1-15. 
Wolkowinski, P. (2018). The MI-FRIENDLY project Journal N 1 . Urban Innovative Actions. https://www.uia-initiative.eu/sites/default/files/2019-02/Coventry_MiFriendly_\%20Jour nal_conv.pdf. Accessed 27 January 2019.

Wu, X., \&Treiman, D. J. (2004). The Household Registration System and Social Stratification in China: 1955-1996. Demography, 41(2), 363-384.

Xie, Y., Lai, Q., \& Wu, X. (2009). Danwei and social inequality in contemporary urban china. Research in the Sociology of Work, 19(19), 283.

Xu, Q. 2007. "Community Participation in Urban China: Identifying Mobilization Factors." Nonprofit and Voluntary Sector Quarterly, 36(4): 622-642.

Zhang, Z., \& Zhang, J. (2015). Social participation and subjective well-being among retirees in china. Social Indicators Research, 123(1), 143-160. 


\section{Tables}

Table 1. Descriptive statistics $(N=4510)$

\begin{tabular}{|c|c|c|c|c|}
\hline & & Percentage (\%) & Mean & SD \\
\hline Age & & & 41.08 & 11.14 \\
\hline Social support & & & 10.19 & 18.99 \\
\hline Education & & & 11.63 & 3.53 \\
\hline Income & & & 51752.45 & 79916.35 \\
\hline Self-reported & & & 3.87 & 0.88 \\
\hline \multicolumn{5}{|l|}{ happiness } \\
\hline & Very unhappy & 1.11 & & \\
\hline & Unhappy & 3.70 & & \\
\hline & Neutral & 28.47 & & \\
\hline & Happy & 40.93 & & \\
\hline & Very happy & 25.79 & & \\
\hline \multirow[t]{6}{*}{ Life satisfaction } & & & 3.77 & 0.90 \\
\hline & Very unsatisfied & 1.42 & & \\
\hline & Unsatisfied & 5.83 & & \\
\hline & Neutral & 28.65 & & \\
\hline & Satisfied & 42.99 & & \\
\hline & Very satisfied & 21.11 & & \\
\hline \multirow[t]{6}{*}{ Health } & & & 3.88 & 0.83 \\
\hline & Very unhealthy & 0.31 & & \\
\hline & Unhealthy & 4.70 & & \\
\hline & Neutral & 25.47 & & \\
\hline & Healthy & 46.11 & & \\
\hline & Very healthy & 23.41 & & \\
\hline \multirow[t]{2}{*}{ Hukou } & Rural & 37.21 & & \\
\hline & Urban & 62.79 & & \\
\hline \multirow[t]{3}{*}{ Mobility } & local & 81.56 & & \\
\hline & migrant & 18.44 & & \\
\hline & Local with rural hukou & 23.26 & & \\
\hline Mobility \& & Local with urban hukou & 58.30 & & \\
\hline \multirow[t]{2}{*}{ hukou } & Migrant with rural hukou & 13.95 & & \\
\hline & Migrant with urban hukou & 4.49 & & \\
\hline \multirow[t]{2}{*}{ Gender } & female & 45.85 & & \\
\hline & male & 54.15 & & \\
\hline
\end{tabular}


Table 2. The rate of social participation in urban China $(N=4510)$

\begin{tabular}{lcc}
\hline & Frequency & Percentage \\
\hline Overall rate of social participation & 720 & $15.83 \%$ \\
Rate of different forms of SP & 188 & \\
$\quad$ Learning/training institution & 149 & $4.17 \%$ \\
Leisure/entertainment/sports club and & & $3.08 \%$ \\
saloon & 73 & \\
Townsmen association & 25 & $1.62 \%$ \\
Clan association & 278 & $0.55 \%$ \\
Residential community committee & 55 & $6.16 \%$ \\
Property owners' committee & 134 & $1.20 \%$ \\
Philanthropic/voluntary organization & 41 & $2.93 \%$ \\
Social work institution & 36 & $0.91 \%$ \\
Religious organization & & $0.80 \%$ \\
\hline
\end{tabular}

Note: SP refers to social participation. 
Table 3-1. Multiple linear regression: self-reported happiness $(N=4510)$

\begin{tabular}{|c|c|c|c|c|c|c|c|c|c|}
\hline & \multicolumn{3}{|c|}{ Model 1} & \multicolumn{3}{|c|}{ Model 2} & \multicolumn{3}{|c|}{ Model 3} \\
\hline & $B(S E)$ & $\begin{array}{c}\beta \\
\text { (stand.) }\end{array}$ & $95 \%$ CI & $B(S E)$ & $\begin{array}{c}\beta \\
\text { (stand.) }\end{array}$ & $95 \%$ CI & $B(S E)$ & $\begin{array}{c}\beta \\
\text { (stand.) }\end{array}$ & $95 \%$ CI \\
\hline Frequency/ SP & & & & $0.04(0.01)$ & $0.06^{* * *}$ & $0.02,0.05$ & & & \\
\hline Diversity/ SP & & & & & & & $0.10(0.02)$ & $0.07^{* * *}$ & $0.06,0.15$ \\
\hline Male & $-0.10(0.03)$ & $-0.06^{* * *}$ & $-0.15,-0.05$ & $-0.10(0.03)$ & $-0.06^{* * *}$ & $-0.15,-0.05$ & $-0.10(0.03)$ & $-0.06^{* * *}$ & $-0.15,-0.05$ \\
\hline Age & $0.00(0.01)$ & 0.01 & $-0.01,0.02$ & $0.00(0.01)$ & 0.02 & $-0.01,0.02$ & $0.00(0.01)$ & 0.02 & $-0.01,0.02$ \\
\hline Age $^{2}$ & $0.00(0.00)$ & 0.05 & $0.00,0.00$ & $0.00(0.00)$ & 0.04 & $0.00,0.00$ & $0.00(0.00)$ & 0.04 & $0.00,0.00$ \\
\hline Income & $0.04(0.02)$ & $0.04^{* *}$ & $0.01,0.07$ & $0.04(0.02)$ & $0.04^{* *}$ & $0.01,0.07$ & $0.04(0.02)$ & $0.04^{* *}$ & $0.01,0.07$ \\
\hline Health & $0.24(0.02)$ & $0.22^{* * *}$ & $0.21,0.27$ & $0.24(0.02)$ & $0.23^{* * *}$ & $0.21,0.27$ & $0.24(0.02)$ & $0.23^{* * *}$ & $0.21,0.27$ \\
\hline Education & $0.03(0.01)$ & $0.10^{* * *}$ & $0.02,0.04$ & $0.02(0.01)$ & $0.10^{* * *}$ & $0.02,0.03$ & $0.02(0.01)$ & $0.09^{* * *}$ & $0.01,0.03$ \\
\hline Social support & $0.00(0.00)$ & $0.05^{* * *}$ & $0.00,0.00$ & $0.00(0.00)$ & $0.05^{* *}$ & $0.00,0.00$ & $0.00(0.00)$ & $0.04^{* *}$ & $0.00,0.00$ \\
\hline Mobility (migrant) & $-0.16(0.04)$ & $-0.07^{* * *}$ & $-0.23,-0.09$ & $-0.16(0.04)$ & $-0.07^{* * *}$ & $-0.23,-0.09$ & $-0.16(0.04)$ & $-0.07^{* * *}$ & $-0.23,-0.09$ \\
\hline hukou (urban) & $-0.03(0.03)$ & -0.02 & $-0.10,0.03$ & $-0.04(0.03)$ & -0.02 & $-0.10,0.03$ & $-0.04(0.03)$ & -0.02 & $-0.10,0.03$ \\
\hline Constant & $2.59^{* * *}(0.18)$ & & $2.23,2.94$ & $2.56^{* * *}(0.18)$ & & $2.21,2.91$ & $2.56^{* * *}(0.18)$ & & $2.21,2.91$ \\
\hline$R^{2}$ & .08 & & & .08 & & & .08 & & \\
\hline Adjusted $R^{2}$ & .07 & & & .08 & & & .08 & & \\
\hline$F$ & $41.21^{* * *}$ & & & $38.92^{* * *}$ & & & $39.40^{* * *}$ & & \\
\hline
\end{tabular}

Note: 1 . SP refers to social participation. 2. Standard error is in the brackets. $3 .{ }^{*} p \leq 0.05,{ }^{* *} p \leq 0.01,{ }^{* * *} p \leq 0.001$. 4 . Collinearity diagnostics were undertaken for the three models, and results show that Tolerance was above 0.1 and VIF was below 10 for all the variables expect Age and Age Square, either of which be deleted exclude Collinearity. 
Table 3-2. Multiple linear regression: life satisfaction $(N=4510)$

\begin{tabular}{|c|c|c|c|c|c|c|c|c|c|}
\hline & \multicolumn{3}{|c|}{ Model 1} & \multicolumn{3}{|c|}{ Model 2} & \multicolumn{3}{|c|}{ Model 3} \\
\hline & $B(S E)$ & $\begin{array}{c}\beta \\
\text { (stand.) }\end{array}$ & $95 \%$ CI & $B(S E)$ & $\begin{array}{c}\beta \\
\text { (stand.) }\end{array}$ & $95 \%$ CI & $B(S E)$ & $\begin{array}{c}\beta \\
\text { (stand.) }\end{array}$ & $95 \%$ CI \\
\hline Frequency/ SP & & & & $0.03(0.01)$ & $0.05^{* * *}$ & $0.01,0.05$ & & & \\
\hline Diversity/ SP & & & & & & & $0.09(0.02)$ & $0.05^{* * *}$ & $0.04,0.13$ \\
\hline Male & $-0.13(0.03)$ & $-0.07^{* * *}$ & $-0.18,-0.08$ & $-0.13(0.03)$ & $-0.07^{* * *}$ & $-0.18,-0.08$ & $-0.13(0.03)$ & $-0.07^{* * *}$ & $-0.18,-0.07$ \\
\hline Age & $-0.01(0.01)$ & 0.12 & $-0.03,0.01$ & $-0.01(0.01)$ & -0.11 & $-0.02,0.01$ & $-0.01(0.01)$ & -0.11 & $-0.02,0.01$ \\
\hline Age $^{2}$ & $0.00(0.00)$ & $0.22^{*}$ & $0.00,0.00$ & $0.00(0.00)$ & $0.21^{*}$ & $0.00,0.00$ & $0.00(0.00)$ & $0.21^{*}$ & $0.00,0.00$ \\
\hline Income & $0.09(0.02)$ & $0.10^{* * *}$ & $0.06,0.12$ & $0.09(0.02)$ & $0.10^{* * *}$ & $0.06,0.12$ & $0.09(0.02)$ & $0.10^{* * *}$ & $0.06,0.12$ \\
\hline Health & $0.24(0.02)$ & $0.22^{* * *}$ & $0.21,0.27$ & $0.24(0.02)$ & $0.23^{* * *}$ & $0.21,0.27$ & $0.24(0.02)$ & $0.23^{* * *}$ & $0.21,0.27$ \\
\hline Education & $0.02(0.01)$ & $0.06^{* * *}$ & $0.01,0.03$ & $0.02(0.01)$ & $0.06^{* *}$ & $0.01,0.02$ & $0.01(0.01)$ & $0.06^{* *}$ & $0.01,0.02$ \\
\hline Social support & $0.00(0.00)$ & $0.04^{* *}$ & $0.00,0.00$ & $0.00(0.00)$ & $0.04^{* *}$ & $0.00,0.00$ & $0.00(0.00)$ & $0.04^{* *}$ & $0.00,0.00$ \\
\hline Mobility (migrant) & $-0.17(0.04)$ & $-0.07^{* * *}$ & $-0.24,-0.10$ & $-0.17(0.04)$ & $-0.08^{* * *}$ & $-0.24,-0.10$ & $-0.17(0.04)$ & $-0.07^{* * *}$ & $-0.24,-0.10$ \\
\hline hukou (urban) & $-0.00(0.03)$ & 0.02 & $-0.06,0.07$ & $0.00(0.04)$ & 0.00 & $-0.06,0.07$ & $0.00(0.03)$ & 0.00 & $-0.06,0.07$ \\
\hline Constant & $2.64^{* * *}(0.18)$ & & $2.23,2.94$ & $2.63^{* * *}(0.18)$ & & $2.27,2.98$ & $2.62^{* * * *}(0.18)$ & & 2.27, 2.98 \\
\hline$R^{2}$ & .08 & & & .08 & & & .08 & & \\
\hline Adjusted $R^{2}$ & .08 & & & .08 & & & .08 & & \\
\hline$F$ & $44.07^{* * *}$ & & & $40.81^{* * *}$ & & & $41.18^{* * *}$ & & \\
\hline
\end{tabular}

Note: 1 . SP refers to social participation. 2. Standard error is in the brackets. $3 .{ }^{*} p \leq 0.05,{ }^{* *} p \leq 0.01,{ }^{* * *} p \leq 0.001$. 4 . Collinearity diagnostics were undertaken for the three models, and results show that Tolerance was above 0.1 and VIF was below 10 for all the variables expect Age and Age Square, either of which be deleted exclude Collinearity. 
Table 4. Mean of SP by mobility and hukou groups ( $N=4510)$

\begin{tabular}{cccccccccc}
\hline & \multicolumn{2}{c}{ Mobility } & \multicolumn{2}{c}{ hukou } & \multicolumn{3}{c}{ Mobility \& hukou } \\
\cline { 2 - 10 } & $\begin{array}{c}\text { Local } \\
\text { resident }\end{array}$ & Migrant & Rural & Urban & Local & Migrant & Local & Migrant \\
& & & & rural & rural & urban & urban \\
\hline Diversity of SP & 0.23 & 0.17 & 0.15 & 0.25 & 0.17 & 0.13 & 0.25 & 0.30 \\
Overall frequency of SP & 0.53 & 0.43 & 0.37 & 0.60 & 0.39 & 0.32 & 0.59 & 0.75 \\
$N$ & 3680 & 830 & 1675 & 2826 & 1047 & 628 & 2624 & 202 \\
\hline
\end{tabular}

Note: SP refers to social participation. 